\title{
Methodological issues in using sequential representations in the teaching of writing
}

\author{
Chien-Ching Lee ${ }^{\mathrm{a} *}$, Jeannette Bopry and John Hedberg ${ }^{\mathrm{b}}$ \\ ${ }^{\mathrm{a} N a n y a n g}$ Technological University, Singapore; ${ }^{\mathrm{b}}$ Macquarie University, Australia
}

This study looks at a specific application of Ainsworth's conceptual framework for learning with multiple representations in the context of using multiple sequential graphic organizers that are student-generated for a process-writing task. Process writing refers to writing that consists of multiple drafts. It may be a process of re-writing without feedback or re-writing based on feedback where the teacher or peers will provide feedback on the original draft and then the students will revise their writing based on the feedback given. The objective was to explore how knowledge of students' cognitive processes when using multiple organizers can inform the teaching of writing. The literature review analyzes the interaction of the design, function and task components of the framework; culminating in instructional approaches for using multiple organizers for classes with students of different writing abilities. Extended implications for designers of concept mapping tools based on these approaches are provided.

\section{Introduction}

Graphic organizers are visual representations of ideas in keyword format. They can be categorized according to function (e.g. compare and contrast, problem and solution) or form (e.g. spider map and tree diagram). Multiple representations, on the other hand, refer to different types of representations in terms of modality (visual, audio or textual) or number (more than one representation of the same type).

The purpose of this paper is to explore how knowledge of students' cognitive processes when using multiple organizers informs the teaching of writing. This paper will present the writing process of poor writers and how graphic organizers scaffold the process, before proceeding to review the use of multiple representations in learning and the methodological issues in the use of sequential graphic organizers in process writing.

*Corresponding author. School of Materials Science and Engineering, Nanyang Technological University, Nanyang Avenue, Singapore 639798, Singapore. Email: leecc@ntu.edu.sg 


\section{Current perspectives on the use of organizers in the teaching of writing}

Research on the writing process of poor writers shows that they do not have a sense of priority. Thus, they spend little time planning and begin writing although they are still confused about the task (Zamel, 1983). They often lack a mental representation of what they are writing as they cannot define their task well (Scardamalia \& Bereiter, 1986a), which leads them to practice knowledge-telling by writing whatever they could recall about the topic without thinking about the structural coherence of their writing or any awareness of audience expectations. They do not have a sense of direction (Perl, 1979) when writing; hence, they use the trial-and-error approach to trigger further writing (Scardamalia \& Bereiter, 1986b). They also have very inflexible plans (Richards, 1990), and do not possess systematic strategies to help them to generate enough content to write. Therefore they are unwilling to discard anything that might 'fit' into the topic. Finally, they tend to think that their lack of composing competence is due to their limited language resources (Richards, 1990), and hence they focus on language issues.

Graphic organizers have often been used to scaffold students' writing. Table 1 shows how graphic organizers can help poor writers.

Drawing graphic organizers may help students to plan their writing in the prewriting stage so that they will have a clear sense of direction when they write. Graphic organizers thus help students to identify what information they should look for, what information is missing and what information is redundant to their writing via visual representation. In a tree diagram, for example, the order of the ideas can be seen clearly by looking at its location within the hierarchy.

Recording notes from text and then reviewing them in an organizer reinforces learning as this allows students to access the information or input twice (once when they record the information into the graphic organizers, and the second time when they review the information represented in their graphic organizers to write their essays). This review also encourages students to re-examine their writing goals in the light of their task goal. Similarly, the visibility of the graphic organizers allows students to manipulate the ideas in the graphic organizers. Students may be prompted to revise an idea that does not fit a cell in a matrix or be encouraged to look for further information due to highlighted gaps in their knowledge. Thus, they can get a clear sense of direction before writing begins.

Flower and Hayes (1980) suggest that if students concentrate on language in the initial stages of writing, this may truncate the flow of their thoughts. The use of

Table 1. Graphic organizers to scaffold writing

\begin{tabular}{ll}
\hline Problems in writing & Benefits of using graphic organizers \\
\hline $\begin{array}{l}\text { No sense of priority } \\
\text { Lack of mental representation, }\end{array}$ & $\begin{array}{l}\text { Forced to fill in ideas and link them into an argument } \\
\text { no sense of direction }\end{array}$ \\
$\begin{array}{l}\text { Inflexible plans } \\
\text { goncermation is indexed by location, reviewing writing }\end{array}$ \\
Concerned about language & $\begin{array}{l}\text { Ideas are easily manipulated } \\
\text { Focus on keywords, not sentence structure }\end{array}$ \\
\hline
\end{tabular}


graphic organizers helps students to concentrate on meaning rather than form (sentences), as only keywords are used in the organizers. Students can also learn to write systematically as they translate the ideas from the organizer into their essays. Practice in writing with organizers may support students in developing richer procedural knowledge about writing. For example, Benton et al. (1993) found that writing notes using a matrix helped students form a coherent overview of the subject, and students who wrote their essays from their notes were more organized and coherent in their writing. They also wrote lengthier essays.

\section{Multiple representations and learning}

There are many advantages to using multiple representations. Mayer (1997) claims in his multimedia theory that students learn better from pictures and words rather than learning from words alone. Two of the assumptions of his multimedia theory explain that this is because working memory is more efficient if information is processed in dual channels as the working memory is limited in its processing capacity. Additionally, he proposes, students need to be active participants in the learning process, selecting and organizing information into coherent representations. This is facilitated by students having to recode information from one modality to another.

Spiro et al.'s (1992) cognitive flexibility theory also supports the use of multiple representations to provide students with situation-sensitive knowledge that would prepare them for problem-solving transfer. Additionally, multiple representations prompt students to compare and contrast the various situations covered so that they avoid reductive bias (premature conclusions based on prior knowledge).

Mayer (2001), however, highlights that there are competitive effects in the use of multiple representations in his instructional design principles for multimedia. $\mathrm{He}$ finds that multiple representations distract students from their focus of attention when there is too much redundant or extraneous information. For example, Mayer and Moreno's (1998) study found that students performed worse in the animation (visual), narration (audio) and on-screen text (visual) group than the animation (visual) and narration (audio) group. Although the information in the visual channel was the same (and thus redundant) but in different forms, students still processed both, which added to their cognitive load. Similarly, Moreno and Mayer (2000) found that students who received the narration, background music and sounds treatment fared the worst. Adding environmental sounds did not interfere with students' understanding of the lightning process being narrated because the stimuli were relevant and coordinated with the narration. However, the background music interfered with students' comprehension of what was being learnt because it was not relevant to their understanding.

Mayer's modality, redundancy and coherence principles are pro-active steps that the teacher needs to take in structuring the task. However, they do not provide enough insights into the use of representations when they are generated by students for sequential processes within a task in a classroom context. Ainsworth's (2006) conceptual framework for learning with multiple representations, however, expands 
on Mayer's principles, by recognizing the different functions of representations and the cognitive tasks that students engage in when using them. Her framework has three components: design, function and task.

The design parameters are number, form, information, sequence and translation. Ainsworth (2006) suggests that the number of representations should be sufficient for the task and not overwhelming. This is because the cognitive tasks involved in using the representations are complex. In addition, students have to be familiar with the form of the representations to be able to select and construct them correctly. Furthermore, how the representations are sequenced (concurrently or sequentially, and in what order) and the way the information is distributed between the representations may not be clear to the students, thus leaving students confused about how to translate (coordinate and integrate information) between representations.

She also recommends that we should first identify the function of the representations to see whether they are complementary, constraining or constructing when providing support for processing. She explains that recognizing the functions of the representations is important as it determines whether the representations have to be co-present when information is processed. If the representations have to be copresent, this would involve a higher cognitive load.

The multiple representations complement each other when they differ in terms of the processes each supports or the information contained. The constraining function happens in two ways: when a familiar representation is introduced prior to an unfamiliar one so that students can learn by analogy, and by explicit illustration. Finally, multiple representations have the constructing function when learners integrate information from the various representations introduced to construct new knowledge that would be difficult to achieve with only one representation.

Ainsworth (2006) also highlights the complexity of the cognitive tasks students perform when using multiple representations, and thus advocates that students be trained to understand, select and construct representations appropriate to the task.

The next section discusses how Ainsworth's model of design, function and cognitive tasks interplay with each other in the context of using multiple graphic organizers in process writing.

\section{Methodological issues in using sequential graphic organizers in writing}

Process writing requires students to write multiple drafts based on feedback from their peers or teacher. The writing process could also be divided into three stages: categorizing and extracting, integrating information and drawing conclusions. Thus, for each stage, students are to write their drafts, comment on each others' drafts, and revise their drafts based on their peers' feedback and, finally, based on their teacher's feedback. Peer feedback helps to provide students with a mental model of readers (Berg, 1999), multiple perspectives of what is being learnt (van Boxtel et al., 2000) and expand their understanding (Witbeck, 1976) so that students are clearer about any incongruity between their ideas and how their ideas are perceived by their audience. In addition, feedback by the teacher helps to provide students with the motivation to 
revise in a multi-draft setting (Jacobs et al., 1998). What are the issues involved if these textual drafts are replaced by 'organizer' drafts?

\section{Number and sequence}

In process writing, the organizers have a complementary function. Thus, the organizers are generated, commented and revised sequentially according to the purposes of each stage of the writing process.

This creates the split attention effect. To overcome this problem, Pollock et al. (2002) suggest that teachers should first isolate the interacting elements and then introduce them simultaneously in order to lessen students' cognitive load. This is because as long as students do not have a basic schema in long-term memory, learning will be impeded because of the high cognitive load. In a class with students of mixed abilities in writing, the implication may mean that students should not be allowed to write their essays until they have their ideas represented in the organizers coherently.

Sweller (2004), however, cautions that this strategy may have the expertise reversal effect on expert writers because if a 'knowledge-based central executive is already available, an instruction-based version will be redundant and may interfere with additional learning' (p. 25). Seufert's (2003) results also show that students with high prior knowledge do not seem to benefit from instruction using multiple representations. In fact, instruction interferes with their mental model construction. Mayer (1997) also agrees that students with high prior knowledge seem to be able to construct a mental model of the content studied just from text, without the aid of visuals.

Thus it may be better then to encourage students with high prior knowledge to use organizers with the constructing function, while students with low prior knowledge should be introduced to organizers with constraining and complementary functions to support their learning.

An alternative would be for teachers to consider giving students the choice and flexibility in the number of organizers that need to be generated, commented on and revised. This means that teachers have to be selective as to which process they want to make compulsory for students to enjoy the benefits of process writing. It is suggested that support for processing should be focused on the initial stages of writing; namely, the categorizing and extracting information process rather than the later stages. This is in line with Ferris's (1997) finding that students are most likely to revise in the early stages of writing compared with later stages.

\section{Form}

Schnotz and Bannert (2003) find that inappropriate selection of representations may impede students' mental model construction. Thus, training is important to enable students to understand, select and construct the organizers appropriate for the task. Winn (1993) states that students' knowledge of the content of the diagram lets students anticipate what to look for next and where to look for it. 
Griffin et al. (1995) also agree that training is important in helping students optimize the features of the organizers. Their results show that, in the absence of explicit instructions, the performance of the students is similar to rereading the text. This is because students are not able to relate the new information in the text to the existing information in the organizer (Kloster \& Winne, 1989). Chmielewski and Dansereau (1998) further find that, with training, students are able to recall more macro-level ideas than students not trained in the construction and use of the knowledge map.

Ainsworth (2006) and Cheng et al. (2001) further highlight that the computational offloading, re-representation and constraining properties of the representations should all be considered, since different properties of the representations may have different effects on students' elaboration. Students have to re-represent their ideas from one representation to another for the different stages in writing. In addition, students need to understand the relationship between the constrained and the constraining representation if they are to translate between representations. The different representations also offer different computational offloading properties, thus triggering students to use different strategies when trying to understand them. Ainsworth et al. (2002), for example, show that students use perceptual strategies when using pictorial representations but rule-based strategies when using mathematical representations.

Stark et al. (2002) suggest that elaboration training (ability to draw inferences from worked examples) should be given to help students improve the quality of their example elaboration (in this context, students' revision). Their study shows that students with elaboration training mostly used deep cognitive elaboration, which was also associated with a tolerance for ambiguity, while students without elaboration training used superficial elaboration.

\section{Information}

The way information is distributed among the sequential organizers also affects students' processing. Ainsworth et al.'s (2002) study found that students have difficulties translating between representations. Students in the pictorial and mathematical condition (mixed) did not improve as compared with those given only one type of representation. When the study was repeated, the mixed group improved as they learnt to focus on the representation that contained all the relevant information and ignore the other representation. This may mean that metacognitive instruction is important to raise students' awareness about the different purposes of each stage in the writing process in the early stages of instruction. Sweller (2004) also agrees that explanations should be given in the early stages. This will enable students to concentrate on generating, commenting and revising the content when using the organizers.

\section{Translation}

Students have difficulties translating between representations because of the form of the representations and their processing strategies. Lowe (2003) reports that students 
have difficulties identifying conceptually significant information in static graphics as they are not salient. Lewalter's (2003) study further shows that rehearsal strategies (memorizing and recapitulation) are the most frequently used strategies when students are studying static and dynamic visuals. Students very rarely use elaboration strategies (building connections between new information and prior knowledge) and control strategies (strategies to plan and regulate learning). This result is similar to Paulus' (1999) finding that students often engage in superficial revisions; namely, paraphrasing or rewording rather than meaning-level revisions.

Mayer and Sims's (1994) study also found that students with different spatial abilities process information differently. Their results show that students with high spatial ability are able to devote more cognitive resources to building referential connections (interacting connections) between visual and verbal representation, while students with low spatial ability devote more cognitive resources to building representation connections between visually presented material and its visual representation.

Thus, teachers should train students in giving peer review and revising following Faigley and Witte's (1981) taxonomy of revision changes in text and Stark et al.'s (2002) coding system for elaboration behavior, so that they can see the type of comments on which they have focused (Figure 1) and, on the part of the writers, the type of revisions in which they have engaged (Figure 2). This is greatly facilitated by organizers that offer computational offloading, re-representation and constraining properties which are hierarchical in nature (have a heading and sub-heading structure) as they help students see the focus of their changes.

The following explanation presents an adaptation of Faigley and Witte's (1981) taxonomy for use in analyzing graphic organizers. Surface comments in the organizers

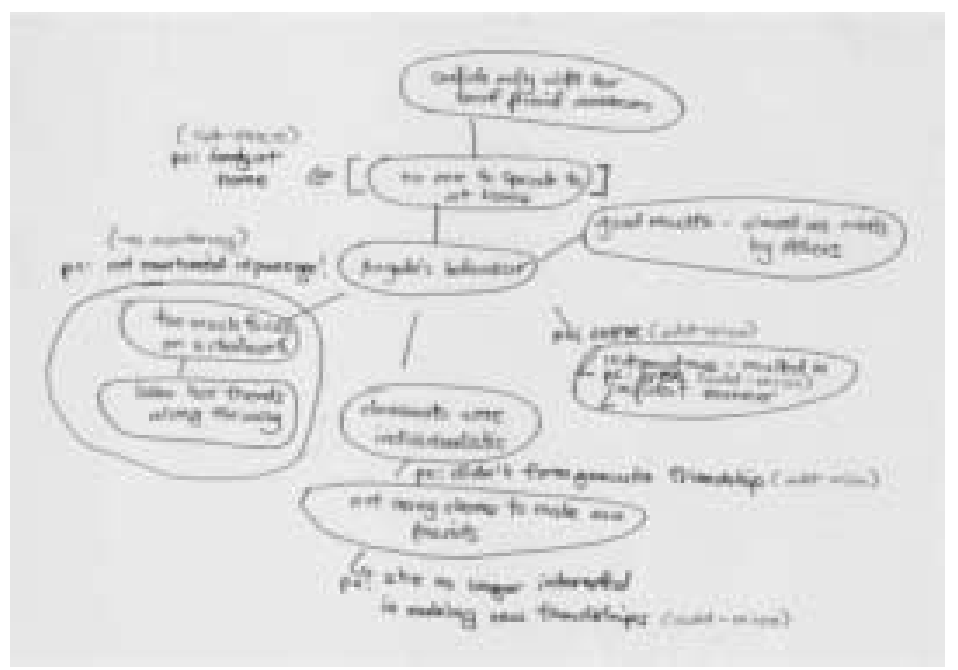

Figure 1. Sample showing peer comments coded using Faigley and Witte's (1981) and Stark et al.'s (2002) categories. Note: pc refers to peer comments. Categorizations in parentheses refer to type of comments 


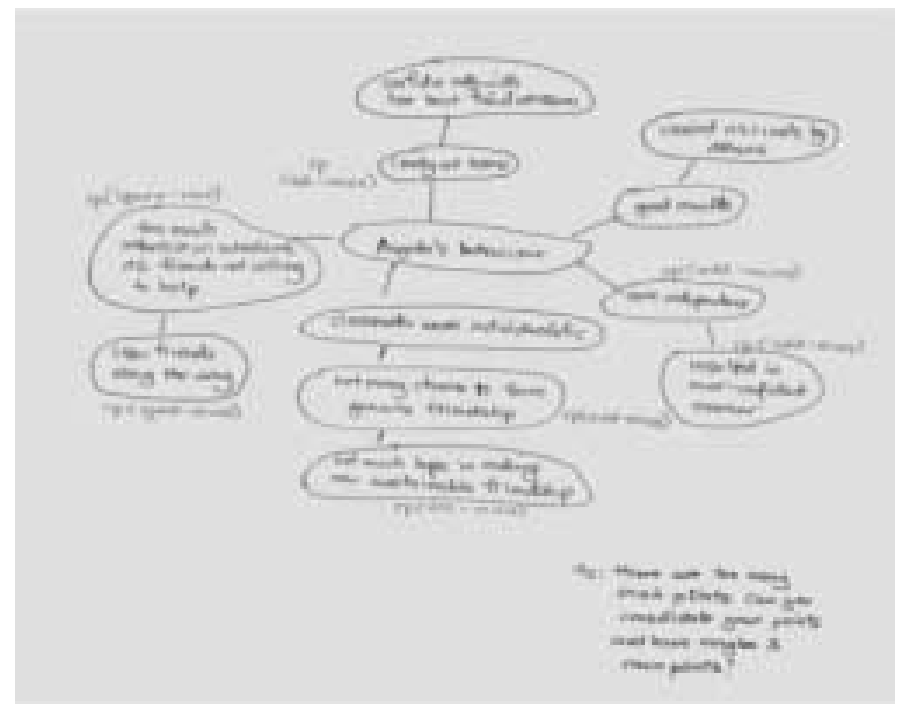

Figure 2. Sample showing a student's revisions based on peer comments. Note: rp refers to revision based on peers' comments, and tc refers to teacher comments. Categorizations in parentheses refer to type of revision made

consist of formal comments affecting the spelling of words. Text-base comments are based on the location of the idea being commented on. If the comment concerns a main idea, it is considered a macro comment. Addition macro comments add a main idea into the organizer, while deletion macro comments delete a main idea from the organizer. Substitution macro comments refer to comments where the peer deletes the original main idea and substitutes another main idea in the same location. Distribution macro comments refer to instances where the peer may want to change a main idea into a sub-idea of another main idea. Consolidation macro comments, on the other hand, refer to instances where the peer combines two main ideas to form a new main idea.

Stark et al.'s (2002) coding system includes goal-operator comments and monitoring elaboration. Goal-operator comments occur when students are out-of-topic or when their peers feel that the students' ideas do not meet the audience's needs and purpose of the writing task. Positive monitoring comments occur when the peers affirm that they understand what the students have written as it is presented well. Negative monitoring comments occur when the peers mention that they do not understand what the students are trying to present. This may be because the organizers are too brief. The same categorizations apply to micro-comments except that it is at the sub-idea level. Students' revisions can be similarly analyzed with the addition of one more category; that is, to ignore their peers' or teacher's comment at the macro or micro level of ideas.

Table 2 outlines the proposed instructional approaches suitable for classes with students of different writing abilities in the order they should be introduced in the classroom as gleaned from the discussion above. 
Table 2. Instructional approaches for classes according to students' writing ability

\begin{tabular}{|c|c|c|c|}
\hline Approach & $\begin{array}{l}\text { Class with } \\
\text { good writers }\end{array}$ & $\begin{array}{l}\text { Class with good and } \\
\text { poor writers }\end{array}$ & Class with poor writers \\
\hline $\begin{array}{l}\text { Simultaneous introduction of } \\
\text { different elements }\end{array}$ & Yes & $\begin{array}{l}\text { No (isolate-interacting } \\
\text { approach) }\end{array}$ & $\begin{array}{l}\text { No (isolate-interacting } \\
\text { approach) }\end{array}$ \\
\hline $\begin{array}{l}\text { Awareness of the purpose of } \\
\text { each stage of the writing } \\
\text { process }\end{array}$ & Yes & Yes & Yes \\
\hline $\begin{array}{l}\text { Awareness of how information } \\
\text { is distributed among the } \\
\text { different representations for } \\
\text { each stage }\end{array}$ & Yes & Yes & Yes \\
\hline $\begin{array}{l}\text { Number of stages required for } \\
\text { feedback }\end{array}$ & $\begin{array}{l}\text { Less (only the } \\
\text { first stage) }\end{array}$ & $\begin{array}{l}\text { Compulsory for the first } \\
\text { stage and optional for } \\
\text { the later stages }\end{array}$ & All the stages \\
\hline $\begin{array}{l}\text { Training in selection and } \\
\text { construction of the organizers }\end{array}$ & Yes & Yes & Yes \\
\hline Training in peer review & Yes & Yes & Yes \\
\hline $\begin{array}{l}\text { Training in example } \\
\text { elaboration }\end{array}$ & Optional & Yes & Yes \\
\hline $\begin{array}{l}\text { Time to complete the } \\
\text { assignment }\end{array}$ & Less time & More time & $\begin{array}{l}\text { More time, with less } \\
\text { assignments }\end{array}$ \\
\hline
\end{tabular}

\section{Implications}

Four main implications arise from the above approaches for designers of concept mapping tools. Firstly, visual mapping software should have multiple-entry levels for users with different writing abilities. Good writers should have the option to map the ideas for the whole essay in one screen while poor writers should have the option to map their ideas one stage at a time. A further option should be provided where students can choose to view ideas at certain hierarchies (e.g. top level and sub-idea level 1 for all the main points simultaneously to check for flow) or just focus on one main idea with all its sub-ideas for further elaboration. Secondly, a small comment box could be added to remind users of the purpose of each stage and how information is distributed among the different representations. This would help writers keep a mental blueprint of what they are doing and not be lost in the details. Thirdly, as different organizers offer different computational offloading, re-representation and constraining properties and students do have preferences regarding the organizers used (Lee, 2005), students need to be trained to select and construct appropriate organizers. Finally, training in peer review and example elaboration also needs to take into account the 'inflexibility' and time taken to map ideas using software compared with mapping ideas using pen and paper. In order to offset these disadvantages, it would be advantageous if mapping software could provide a 'track changes' view that could be enabled or disabled according to the students' choice. This view would label 
the changes in terms of micro and macro changes; and also types of changes according to Faigley and Witte's (1981) taxonomy of revision changes to motivate students to do meaning-level revisions rather than just paraphrasing ideas.

\section{Conclusion}

This paper has considered a specific application of Ainsworth's framework for the use of multiple representations in writing, by looking at how the knowledge of students' decisions with regards to the usage of graphic organizers generated sequentially inform the teaching of writing. From the literature review, we have proposed instructional approaches for the use of multiple graphic organizers for classes with students of different writing abilities. Extended implications for designers of concept mapping tools based on these approaches have also been provided. It is hoped that these insights will provide for further development of Ainsworth's framework for use in other contexts.

\section{References}

Ainsworth, S. (2006) DeFT: a conceptual framework for considering learning with multiple representations, Learning and Instruction, 16, 183-189.

Ainsworth, S., Bibby, P. \& Wood, D. (2002) Examining the effects of different multiple representational systems in learning primary mathematics, The fournal of the Learning Sciences, 11(1), 25-61.

Benton, S. L., Kiewra, K. A., Whitfill, J. M. \& Dennison, R. (1993) Encoding and externalstorage effects on writing processes, fournal of Educational Psychology, 85(2), 267-280.

Berg, E. C. (1999) The effects of trained peer response on ESL students' revision types and writing quality, fournal of Second Language Writing, 8(3), 215-241.

Cheng, P. C. H., Lowe, R. K. \& Scaife, M. (2001) Cognitive science approaches to understanding diagrammatic representations, Artificial Intelligence Review, 15, 79-94.

Chmielewski, T. L. \& Dansereau, D. F. (1998) Enhancing the recall of text: knowledge mapping training promotes implicit transfer, fournal of Educational Psychology, 90(3), 407-413.

Faigley, L. \& Witte, S. (1981) Analyzing revision, College Composition and Communication, 32, 400-414.

Ferris, D. (1997) The influence of teacher commentary on student revision, TESOL Quarterly, 31(2), 315-339.

Flower, L. S. \& Hayes, J. R. (1980) The dynamics of composing: making plans and juggling constraints, in: L. W. Gregg \& R. S. Erwin (Eds) Cognitive processes in writing (Hillsdale, NJ Lawrence Erlbaum Associates).

Griffin, C. C., Malone, L. D. \& Kammenui, E. J. (1995) Effects of graphic organizer instruction on fifth-grade students, Fournal of Educational Research, 89(2), 98-107.

Jacobs, G. M., Curtis, A., Braine, G. \& Huang, S. Y. (1998) Feedback on student writing: taking the middle path, Fournal of Second Language Writing, 7(3), 307-317.

Kloster, A. M. \& Winne, P. H. (1989) The effects of different types of organizers on students' learning from text, Fournal of Educational Psychology, 81(1), 9-15.

Lee, C. C. (2005) Students' choice of organizers based on their perceptual operations, paper presented at the E-Learn Conference, Vancouver, Canada, 24-28 October.

Lewalter, D. (2003) Cognitive strategies for learning from static and dynamic visuals, Learning and Instruction, 13(2), 177-189. 
Lowe, R. K. (2003) Animation and learning: selective processing of information in dynamic graphics, Learning and Instruction, 13(2), 157-176.

Mayer, R. E. (1997) Multimedia learning: are we asking the right questions?, Educational Psychologist, $32,1-9$.

Mayer, R. E. (2001) Multimedia learning (Cambridge, Cambridge University Press).

Mayer, R. E. \& Moreno, R. (1998) A split-attention effect in multimedia learning: evidence for dual processing systems in working memory, fournal of Educational Psychology, 90, 312-320.

Mayer, R. E. \& Sims, V. K. (1994) For whom is a picture worth a thousand words? Extensions of a dual-coding theory of multimedia learning, fournal of Educational Psychology, 86, 389-401.

Moreno, R. \& Mayer, R. E. (2000) A learner-centered approach to multimedia explanations: deriving instructional design principles from cognitive theories, Interactive Multimedia Electronic Fournal of Computer-Enhanced Learning, 2(2). Available online at: http://imej.wfu. edu/articles/2000/2/05/index.asp (accessed 24 October 2005).

Paulus, T. M. (1999) The effect of peer and teacher feedback on student writing, fournal of Second Language Writing, 8(3), 265-289.

Perl, S. (1979) The composing processes of unskilled college writers, Research in the Teaching of English, 13(4), 317-336.

Pollock, E., Chandler, P. \& Sweller, J. (2002) Assimilating complex information, Learning and Instruction, 12, 61-86.

Richards, J. C. (1990) The language teaching matrix (Cambridge, Cambridge University Press).

Scardamalia, M. \& Bereiter, C. (1986a) Writing, in: R. F. Dillon \& R. J. Sternberg (Eds) Cognition and instruction (Orlando, FL, Academic Press Inc.).

Scardamalia, M. \& Bereiter, C. (1986b) Research on written composition, in: M. C. Wittrock (Ed) Handbook of research on teaching (3rd edn) (New York, American Educational Research Association).

Schnotz, W. \& Bannert, M. (2003) Construction and interference in learning from multiple representation, Learning and Instruction, 13(2), 141-156.

Seufert, T. (2003) Supporting coherence formation in learning from multiple representations, Learning and Instruction, 13, 227-237.

Spiro, R. J., Feltovitch, P. J., Jacobson, M. J. \& Coulson, R. L. (1992) Knowledge representation, content specification and the development of skill in situation-specific knowledge assembly: some constructivist issues as they relate to cognitive flexibility theory and hypertext, in: M. P. Driscoll (Ed.) Psychology of learning for instruction (Boston, MA, Allyn and Bacon).

Stark, R., Mandl, H., Gruber, H. \& Renkl, A. (2002) Conditions and effects of example elaboration, Learning and Instruction, 12(1), 39-60.

Sweller, J. (2004) Instructional design consequences of an analogy between evolution by natural selection and human cognitive architecture, Instructional Science, 32, 9-31.

van Boxtel, C., Linden, J. \& Kanselaar, G. (2000) Collaborative learning tasks and the elaboration of conceptual knowledge, Learning and Instruction, 10(4), 311-330.

Winn, W. (1993) An account of how readers search for information in diagrams, Contemporary Educational Psychology, 18, 162-185.

Witbeck, M. C. (1976) Peer correction procedures for intermediate and advanced ESL composition lessons, TESOL Quarterly, 10(3), 321-326.

Zamel, V. (1983) The composing processes of advanced ESL students: six case studies, TESOL Quarterly, 17(2), 165-187. 